\title{
Lipomas in Inguinal Hernia in a Nigerian Community
}

\author{
Wilson Onuigbo ${ }^{1}$, and Gabriel Njeze ${ }^{2}$
}

\author{
${ }^{1}$ Department of Pathology, Medical Foundation \& Clinic, 8 Nsukka Lane, Enugu 400001, Nigeria \\ ${ }^{2}$ Department of Surgery, Enugu State University of Technology, Teaching Hospital, Park Lane, Enugu 400001, \\ Nigeria
}

\begin{abstract}
Background: Inguinal hernia is a common surgical problem but it can become problematic, when it exhibits some unusual contents. Aim: To highlight the occurrence of lipoma in hernia in a Nigerian community. Materials and methods: From 1977-1980, sacs which were excised during repair of inguinal hernias in the Igbos of South Eastern Nigeria were submitted to a Central Pathology Laboratory. They were studied by naked eye appearances and histologically. Results One hundred and thirty five inguinal hernia sacs were studied, out of which 113 were from males and 22 from females, i.e., a ratio of 6:1. Two sacs contained lipomas. Conclusion The presence of lipomas in inguinal hernia sacs is documented in a Nigerian community as an epidemiological contribution to the world literature.
\end{abstract}

Keywords: Lipoma, Inguinal hernia sac, Igbos, epidemiology

\section{Introduction}

Inguinal hernia repair is one of the most common operations in surgical practice [1]. In spite of their great incidence, hernias can pose a surgical dilemma, even for the skilled surgeon, because an occasional pathologic entity can masquerade in it, a dilemma usually caused by some unexpected contents [2-3]. Therefore, the lipoma is exemplified here with emphasis on its being dissected and excised whenever feasible [4].

\section{Materials and methods}

From 1977-1980, the surgical specimens removed at inguinal herniorrhaphy from Igbos in different hospitals were received at a Reference Pathology Laboratory in Enugu, South Eastern Nigeria. A total of 135 specimens were analyzed with respect to sex, age and any abnormal content in the sac.

\section{Results}

During the three year period (1977-1980), inguinal hernia sacs from 135 Igbo patients aged 9-69 years were received. One hundred and thirteen $(83.7 \%)$ were males and $22(6.3 \%)$ were females, a ratio of $6: 1$. Out of these specimens, 2 contained lipomas. One was from a male patient aged 34 years, and the other from a female aged 45 years. The former was particularly bulky. The histological examination confirmed the presence of lipomas.

\begin{abstract}
Discussion
In some cases, the lipoma is the only finding in the body [5]. A lipoma in the hernia sac may appear to originate from the retroperitoneal fat outside and posterior to the internal spermatic fascia [6]. It is possible that the lipoma insinuates itself through the internal ring and, over some time, dilates it. Fawcett and Rooney performed a prospective examination of 140 hernias and found only one "true" lipoma [7]. Nyhus at al described lipomas of the cord as preperitoneal fat that projects through the internal ring [8]. Apparently, the lipoma may be the only pathology identified during an exploration for a hernia repair. Incidentally, there is a propensity for lipomas to present in women as groin pain or acute appendicitis [9]. This may be due to the usually small size of the internal ring in women, which could allow a smaller lipoma to be symptomatic. However, the lipoma needs to be resected because it has been shown to grow very large. Indeed, in males it can grow into the scrotum and cause diagnostic confusion [10].
\end{abstract}

\section{Conclusion}

Hitherto, lipomas had been classified according to their situations, i.e., subsynovial, extradural, subcutaneous, intramuscular, submucosal, intraglandular, parosteal, subserosal and intraarticular types. We suggest that the inguinal hernia 
sac variety should also be added to the world literature as our own epidemiological contribution.

\section{References}

1. Chang YT, Huang CJ, Hsieh JS, Huang TJ (2004) Giant lipoma of spermatic cord mimics irreducible inguinal hernia: a case report. Kaohsiung J Med 20:247-249 http://dx.doi.org/10.1016/s1607-551x(09)70114-7

2. Ballas K, Kontoulis Th, Skouras Ch, et al. (2009) Unusual findings in inguinal hernia surgery: Report of 6 rare cases. Hippokratia 13:169-171

3. Ninos A, Douridas G, Liapi G, et al. (2004) Schwannoma in the inguinal canal masquerading an inguinal hernia. Hernia 6:73-75 http://dx.doi.org/10.1007/s10029-003-0146-9

4. Nasr AO, Tormey S, Walsh TN (2005) Lipoma of the cord and round ligament: an overlooked diagnosis? Hernia 9:245247 http://dx.doi.org/10.1007/s10029-005-0335-9

5. Lau H (2004) Sliding lipoma: an indirect inguinal hernia without a peritoneal sac. J Laparoendosc Adv Surg Tech A. 14:57-59 http://dx.doi.org/10.1089/109264204322862388

6. Lilly MC, Arregui ME (2002) Lipomas of the cord and round ligament. Ann Surg 235:586-590 http://dx.doi.org/10.1097/00000658-200204000-00018

7. Fawcett AN, Rooney PS (1997) Inguinal cord lipoma.Br J Surg 84:1168-1169 http://dx.doi.org/10.1046/j.13652168.1997.02752.x

8. Nyhus LM, Bombeck CT, Klein MS (1991) Hernias. In Sabiston DC, ed. Textbook of Surgery: The Biological Basis of Modern Surgical Practice, 14th ed. Philadelphia: WB Saunders; 1134-1148

9. Miller TJ, Paulk DG (2013) Round ligament lipoma mimicking acute appendicitis in a 24-week pregnant female: a case report. Hernia 17:259-261 http://dx.doi.org/10.1007/s10029-011-0862-5

10. Vashu R, Subramaniam M (2009) Large lipoma of the spermatic cord presenting as post-operative recurrent hernia in a middle aged gentleman: a case report. Cases J 2:8500 doi: $10.4076 / 1757-1626-2-8500$

http://dx.doi.org/10.4076/1757-1626-2-8500 